\title{
EDUCAÇÃO MATEMÁTICA COM A INSERÇÃO DAS TECNOLOGIAS DE INFORMAÇÃO E COMUNICAÇÃO: UMA PROPOSTA DE RECONSTRUÇÃO DO PROCESSO DE ENSINO E APRENDIZAGEM
}

\author{
Simone de Paula Rodrigues Moura UniEVANGÉLICA/SME \\ simonepaularodrigues@gmail.com \\ Maria Aparecida Fonseca SME/UFG \\ cidafonseca.rodrigues@gmail.com
}

\begin{abstract}
Resumo: Este artigo apresenta diferentes olhares sobre as novas tecnologias e a educação matemática. As atividades docentes desenvolvidas atualmente possibilitam reflexões e alternativas teórico-metodológicas na utilização das tecnologias de informação e comunicação (TICs) nos cursos de formação de professores. Assim, a princípio busca-se diferenciar Matemática e Educação Matemática. Prossegue-se com o diálogo sobre a Educação Matemática com inserção das (TICs). Por fim menciona-se a criação de um blog para o conhecimento e mediação na capacitação de acadêmicos do curso de pedagogia da UniEVANGÉLICA, objetivando não apenas a compreensão de tais tecnologias e os conceitos da ciência em estudo, mas como uma proposta de reconstrução do processo de ensino e aprendizagem.
\end{abstract}

Palavras-chave: Educação Matemática; Formação de Professores; TICs

\section{INTRODUÇÃO}

O uso das tecnologias de informação e comunicação na educação, não é assunto recente. Muitas são as discussões que tem surgido ao longo dos tempos, e uma delas está ligada ao ensino da matemática, logo, ao buscar a compreensão deste a partir da inserção daquelas, visando à reconstrução do processo de ensino e aprendizagem a complexidade do processo se amplia.

$\mathrm{Na}$ atualidade as crianças adentram as unidades escolares, com uma vasta gama de experiências com as tecnologias e muitas encontra uma escola tradicional, com metodologias arcaicas desvinculadas de toda e qualquer mediação por recursos tecnológicos, o que acaba contribuindo para a ineficiência da aprendizagem. Dessa forma, acreditando que a escola pode 


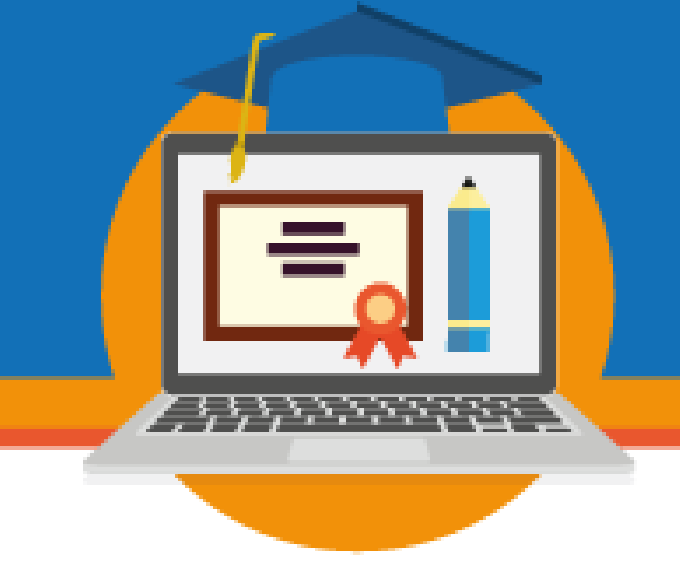

possibilitar novas formas de ensinar e aprender, principalmente a Matemática é que se propõem este estudo, onde a princípio busca-se a compreensão e a diferenciação do que é a Matemática e a Educação Matemática, dando sequência na discussão sobre a Educação Matemática e o uso das TICs e por fim, vivencia-se a inserção das tecnologias, como proposta de reconstrução do processo de ensino e aprendizagem.

\section{MATEMÁTICA E EDUCAÇÃO MATEMÁTICA}

Segundo D’Ambrosio (1996), “a matemática que se ensina hoje nas escolas é morta, vista pelo ponto de motivação contextualizada" (p.31). Pouco da matemática do passado serve para os dias atuais. A matemática de hoje deve estar relacionada ao cotidiano, visando ao interesse dos alunos.

D’ Ambrosio (1996) ${ }^{1}$ elabora, ainda, uma breve introdução à matemática e à sua história e defende que o Movimento da Matemática Moderna (MMM) não alcançou os resultados almejados. Para ele, na década de 1970, o MMM foi declinando em todo o planeta. Porém, esclarece que esse movimento deixou contribuições relevantes no modo de conduzir as aulas, e dentre elas, evidência as atividades variadas em simetria com o protagonismo do aluno, já que por meio da participação efetiva do discente acontece à aprendizagem, o que não era possível visualizar anteriormente, em meio à metodologia das contas pelas contas e suas correções.

Assim, destaca contribuições para uma nova pedagogia de métodos de projetos, com temas variados e uma abertura para iniciar-se um novo trabalho visando a Educação Matemática.

Neto (2001) esclarece como surgiu a MMM e tem a mesma opinião de D' Ambrosio, sobre esse movimento ter influenciado o ensino de Matemática no Brasil e em vários outros países:

... o movimento que se convencionou chamar de "Matemática Moderna", com larga repercussão no mundo a partir da década de 60 . Penso que nem todos sabem que esse movimento, cujo núcleo de

\footnotetext{
${ }^{1}$ Para melhor compreensão da história da Matemática, sugerimos a leitura, entre outras, do capítulo 2 da obra de D’Ambrosio (1996).
} 
estudos experimentais feitos por psicólogos sobre a maneira como as crianças aprendiam a matemática. Nessa perspectiva, o educador matemático esforça-se para priorizar a matemática a serviço da educação.

Em síntese, a Educação Matemática “possui objetos distintos de estudo, cada qual com sua problemática específica, tendo suas próprias questões investigativas" (FIORENTINI; LORENZATO, 2007, p.4).

Fiorentini e Lorenzato (2007) ainda destaca que em vários países passou-se a utilizar a denominação "Educação Matemática". A preferência é atribuída ao fato de que essa conotação é mais abrangente e pode significar fenômeno ou atividade educacional visando à formação integral do cidadão, explorando a área multidisciplinar do conhecimento.

Pesquisadores como Souza (1992), Floriani (2000), Skovsmose e Valero (2001), que atuam em diferentes contextos, têm realizado estudos e defendem em comum, quatro pontos fundamentais à Educação Matemática: contextualização do ensino, respeito à diversidade, desenvolvimento de habilidades e reconhecimento das finalidades científicas, sociais, políticas e histórico-culturais.

Retornando ainda as ideias de Fiorentini e Lorenzato (2007) percebe-se que até o final dos anos de 1960, os poucos estudos referentes à Educação Matemática diziam respeito, quase que totalmente, ao ensino primário. Mas na década de 1970, outros níveis de ensino passaram a interessar-se pelo objeto de estudo sistemático. De 26 estudos produzidos, cinco referiam-se aos anos iniciais, dez ao Ensino Fundamental II, seis ao Ensino Médio e cinco ao Ensino Superior.

Em resumo, o período que representa o surgimento da Educação Matemática no campo profissional de especialistas em didática e metodologia do ensino da Matemática foi nos anos 1970 e no início dos anos 1980.

Para Fiorentini e Lorenzato (2007), das 80 dissertações/teses produzidas nesse período, praticamente todas relatavam pedagogicamente a tendência tecnicista, em que era subtendida uma relação dicotômica entre o papel do professor e do pesquisador especialista. Nessa perspectiva, o papel do professor seria o de aplicar com eficiência os métodos ou propostas 
metodológicas produzidas pelo pesquisador especialista, sendo apenas para conseguir essa titulação, pois as iniciativas eram individuais e isoladas. Não havia ainda uma comunidade nacional organizada e articulada que orientasse o pesquisador na reflexão-ação da Educação Matemática.

Os estudos realizados pelos autores citados acima demonstram que na década de 1980, no Brasil, ocorreu uma intensa e diversificada pesquisa em Educação Matemática, graças à colaboração de vários profissionais, que mesmo sem formação específica na área pedagógica, investiram no campo de produção de conhecimentos. Com isso, surgiram mais de 120 dissertações/teses em 30 programas de Pós-Graduação no país, tomando quase todas as dimensões da Educação Matemática como objeto de estudo. Destacam ainda que no início dos anos de 1990, retornaram ao Brasil mais de 20 educadores matemáticos que haviam concluído doutorado nos Estados Unidos, França, Inglaterra e Alemanha, em áreas diferentes de investigação.

Esses pesquisadores ainda apontam que no Brasil, havia um número ainda maior de educadores matemáticos que também tinham concluído doutorado em cursos de Pós-Graduação em educação. Reunindo todos os doutores que passaram a se dedicar exclusivamente ao campo da Educação Matemática, no final dos anos 1990, havia uma comunidade de, aproximadamente, 200 doutores fazendo da Educação Matemática seu principal campo de atividade profissional, sem contar os nãos doutores que estavam trabalhando exclusivamente com essa área.

Fiorentini e Lorenzato, (2007) afirmam que com toda essa propagação, a área passou a ser reconhecida pela Associação Nacional de Pós-Graduação e Pesquisa em Educação (ANPEd), sendo aprovada em 1997 a constituição de um Grupo de Trabalho (GT) ${ }^{2}$ de Educação Matemática. Assim, passaram a acontecer reuniões anuais com a finalidade de promover o movimento nacional de formação de grupos de pesquisa, criação de novas linhas ou focos de investigação e discussão a respeito da metodologia de pesquisa em Educação Matemática.

\footnotetext{
${ }^{2}$ Mais informações sobre a criação do GT em EM poderão ser encontrada site:http://www.scielo.br/scielo.php?script=sci arttext\&pid=S1413-24782004000300006 


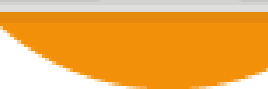

Os autores declaram que nos anos 2000 e 2001, a Capes criou uma nova área de conhecimento: área de ensino de ciências e matemática, proporcionando o funcionamento de dois cursos de doutorado e seis cursos de mestrado acadêmico. Onde, o crescimento de PósGraduação na comunidade científica em Educação Matemática fez com que a Sociedade Brasileira de Educação Matemática $(\mathrm{SBEM})^{3}$ promovesse, além dos Encontros Nacionais de Educação Matemática (ENEMS), o Seminário Internacional de Pesquisa em Educação Matemática (SIPEM) e o Encontro Brasileiro de Estudantes de Pós-Graduação em Educação Matemática (EBRAPEM), tendo esses, como foco, discutir resultados do ensino de matemática, trocar experiências sobre pesquisas no campo da EM e estruturar algumas linhas ou GTs relevantes. No primeiro SIPEM, a comunidade científica de educadores matemáticos organizou-se em doze grupos de trabalho e o de maior relevância para a pesquisa em destaque foi o GT1, que trabalhava com EM nos anos iniciais do Ensino Fundamental.

Analisando o livro de resumos de 2009 no IV SIPEM, ${ }^{4}$ encontram-se 16 trabalhos publicados no GT1 seguindo parcialmente os oito focos temáticos que Fiorentini e Costa (2002) classificam da seguinte maneira: estudos sobre o professor de matemática (seis), estudos cognitivos e meta cognitivos (oito), estudos sobre a produção de significados em atividades matemáticas (um), estudos sobre a matemática em contexto não escolar (um).

Dos 16 resumos, nove se referem ao problema da matemática em relação à formação do professor: falta de conhecimentos específicos, pedagógicos e curriculares. Para amenizar esse problema, Nacarato (2009) sugere alguns fatores favoráveis, como o trabalho compartilhado e colaborativo; as práticas investigativas coletivas e reflexivas e a adoção de práticas de formação que podem desencadear a reflexão e, consequentemente, o desenvolvimento profissional.

Vários pesquisadores brasileiros, vinculados a grupos de estudos de instituições formais ou informais, têm assumido essa dimensão colaborativa para potencializar os fatores citados.

\footnotetext{
${ }^{3}$ Hoje a SBEM conta com cerca de 15.000 associados em todo o país e já realizou dez grandes Encontros Nacionais de Educação Matemática (ENEM) e inúmeros encontros regionais.

${ }^{4} \mathrm{O}$ último livro de resumo de 2012 do V SIPEM, realizado em outubro de 2012, na cidade de Petrópolis, Rio de Janeiro, até o momento desta investigação não estava disponível.
} 


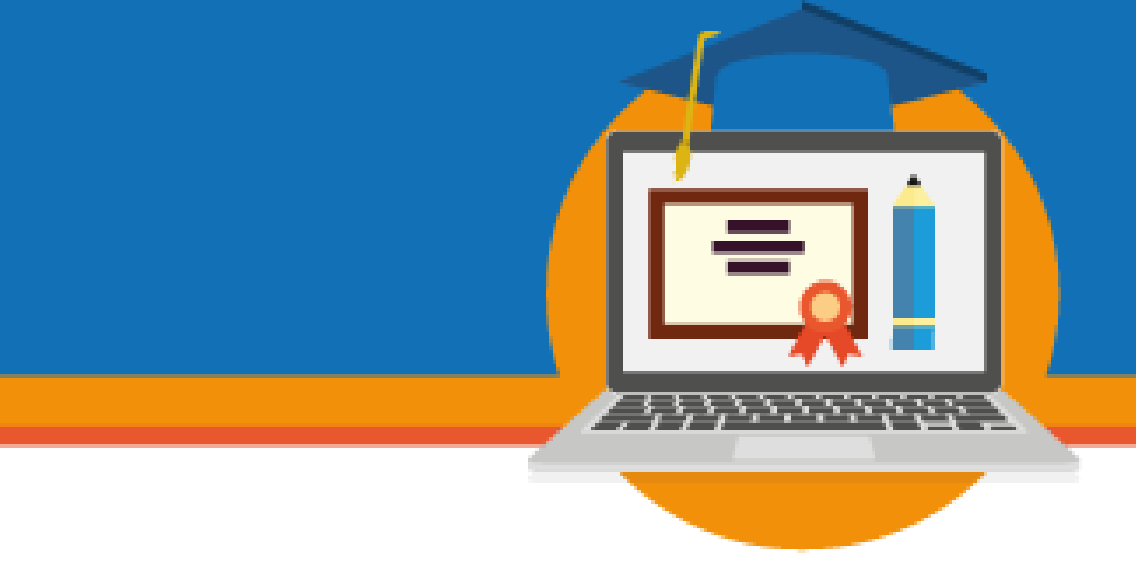

Um desses pesquisadores é Fiorentini (2004) que tem realizado estudos na área da Educação Matemática.

Dos inúmeros trabalhos apresentados por tais iniciativas, 12 se referiam às TICs, mas quase todos com o foco na formação do professor na graduação, na formação continuada ou em programas de Pós-Graduação.

\section{EDUCAÇÃO MATEMÁTICA E O USO DAS NOVAS TICS}

Em inúmeros países, há uma infinidade de iniciativas, governamentais ou não, preocupadas com a capacitação de professores. No Brasil foi criado pelo, então, Ministério da Educação e Desportos (MEC), em 1996, a TV Escola, que é um canal de televisão do MEC com o objetivo de divulgar programas para TV, filmes e noticiários buscando capacitar, aperfeiçoar e atualizar os educadores da rede pública.

Em 1997, foi criado o Programa Nacional de Informática na Educação (ProInfo), com o objetivo de promover o uso pedagógico das Tecnologias de Informação e Comunicação (TICs) na rede pública de Ensino Fundamental e Médio.

Portanova (2005) afirma que, no início, o uso das novas tecnologias não foi aceito com satisfação pelos educadores, e esclarece que isso é comum quando se começa a explorar o desconhecido, até virem à tona todas as vantagens e benefícios. A autora cita várias tecnologias que impactaram a educação, mas que a princípio, também foram muito questionadas, como: a escrita, o lápis, a caneta, o caderno, o livro, o quadro e o giz, entretanto, nos dias atuais estão incorporados ao cotidiano, não sendo impossível pensar a escola, sem tais inventos. $\mathrm{O}$ computador e a internet fazem parte das novas tecnologias e podem trazer inúmeras transformações. Assim, a autora afirma que "A tecnologia tem influenciado na maneira de viver, de se divertir, de informar, de trabalhar, de pensar, de aprender e de aprender a aprender" (PORTANOVA, 2005, p.84).

$\mathrm{Na}$ contemporaneidade a tecnologia influencia a vida das pessoas e direta ou indiretamente as TICs estão envolvidas no processo de ensino e aprendizagem, contudo, apenas 


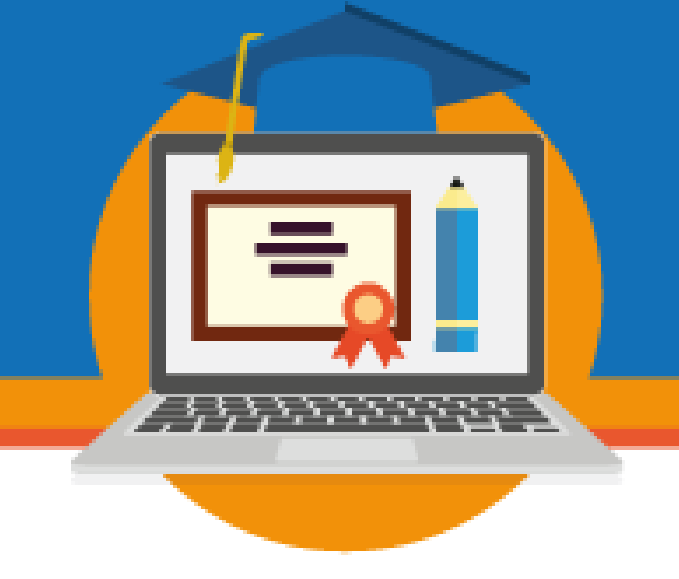

com ações consciente e mediações consistentes, trarão contribuições significativas para a aprendizagem dos alunos.

Um exemplo claro é a substituição dos cálculos exaustivos por cálculos mais rápidos, permitindo a investigação matemática pelo aluno. Na escola, o processo de ensino aprendizagem, com o uso das novas tecnologias, deve ser visto como recurso que possa contribuir "para a formação de seres capazes de analisar e decidir, de abrir caminhos ainda não percorridos, de explorar fatos inexplorados e de transformar a realidade de forma rápida e eficaz" (PORTANOVA, 2005, p. 86).

Cabe aos professores compreender que as TICs podem contribuir ricamente para com o processo de ensino e aprendizagem, entretanto, para que isso aconteça ele deve ser mediador do processo, ensinando ao aluno a transformar informações em conhecimento, proporcionando reflexão e fruição da aprendizagem. Assim ele estará aproveitando todo o potencial pedagógico que as novas tecnologias dispõem, quando incorporadas à educação.

Para Cury (2004), muitos professores da Educação Básica e do Ensino Superior sofrem com as exigências recomendadas pelos Parâmetros Curriculares Nacionais (PCN). A autora cita que, na década de 1990, os alunos reclamavam da falta de computadores nos cursos. Depois de algum tempo, essa reclamação foi atendida com a instalação de laboratórios de computação. Mas agora, as reclamações são outras e dizem respeito à metodologia utilizada pelos professores e até mesmo à recusa dos professores em utilizar as tecnologias.

Os PCNs destacam como competências e habilidades "utilizar adequadamente calculadoras e computador, reconhecendo suas limitações e potencialidades" (BRASIL, 1998, p.45). Cury (2004) concorda com tal posicionamento, pois percebe a necessidade dos profissionais dominarem a tecnologia na sua área de atuação. Percebe-se que a problemática atual não é mais a presença das tecnologias de comunicação e informação no processo educacional, mas sim, o que fazer com tais tecnologias.

Sobre esse assunto, a autora citada anteriormente, alerta que apesar dos documentos legais defenderem o uso das tecnologias, não propõem discussões sobre os porquês, não justificam as razões para o uso e nem explicam como fazê-lo. 
As exigências dos documentos legais, se mal interpretadas, podem provocar mau uso das tecnologias, de acordo com Fonseca (2010) "Muitos professores ainda confundem tecnologia com metodologia e acabam utilizando os recursos de multimeios apenas para ilustrar suas aulas, continuam com as metodologias antigas e tradicionais, as quais limitam os alunos, [...] apenas a decorar conteúdos". (p. 16)

Estudando as ideias de Frota e Borges (2004), entende-se que, para haver o uso efetivo de tecnologias nas escolas e para a efetividade da educação matemática, são necessárias duas mudanças simultâneas principalmente por parte do professor. A primeira seria consumir tecnologia, que acaba sendo um recurso poderoso, tanto para ensinar quanto para aprender matemática. E a segunda seria incorporar tecnologia, na qual o indivíduo toma posse das TICs, mudando a forma de pensar e de fazer matemática.

$\mathrm{Na}$ pesquisa realizada em diversos países, os autores citados acima, identificaram grandes categorias de argumentos, caracterizando três concepções. Ambas são referentes ao papel das novas tecnologias e das TICs, com a possibilidade de representar, na Educação Matemática, e nos documentos de propostas curriculares oficiais, um consumo de tecnologia.

De acordo com Frota e Borges, (2004) a primeira concepção é a mais evidenciada, uma vez que é vista como excelente recurso para aprender e ensinar matemática. É a mais utilizada na comunidade dos professores que lecionam essa disciplina, talvez por ser a mais divulgada nos discursos educacionais de marketing da indústria e do comércio educacional. Nesses discursos, defende-se a ideia de que a educação pode ser mudada pela tecnologia, tornando o processo de ensino aprendizagem mais atrativo, motivador, eficaz e eficiente. Infelizmente, esses discursos acabam ganhando força por conseguir quantidade e qualidade com custos mais baixos para o governo.

Há inúmeros trabalhos que mostram o grande risco de se impactar negativamente a didática e o currículo com o uso das TICs na Educação Matemática, caso se utilizem novas tecnologias somente como um recurso didático para impressionar o aluno. Nesse caso, o professor trabalha com tarefas antigas, dá uma "camuflada", e continua trabalhando com o mesmo ensino convencional. Para Frota e Borges, (2004), essa seria a "visão de consumir 
tecnologia para a automatização de tarefas, mas pode representar um avanço em termos educacionais, na medida em que o foco do ensino de matemática deixar de ser operacional ou procedimental, para assumir uma perspectiva mais conceitual" (p.5).

Pode-se perceber que os professores precisam compreender o que é a Educação Matemática mediada pelas TICs, se familiarizando com o uso dessas tecnologias em experiências pessoais, para que, com o passar do tempo, se vejam capazes de desenvolver novas metodologias possibilitadas por estas tecnologias, propondo os mesmos conteúdos matemáticos priorizados pelos currículos, mas, focalizando aspectos que anteriormente não conseguiam abranger "novas situações e não apenas reformar ou atualizar as metodologias antigas, pois assim, compreendendo tal realidade e inferindo sobre esta, contribuirá para que as TICs, façam educação" (FONSECA 2010, p. 16)

Quando o professor concebe essa mudança tendo como foco a significação das tarefas matemáticas, atingi o segundo nível de entendimento dessa concepção: "consumir tecnologia para mudar o foco das tarefas" (FROTA E BORGES, 2004, p.5). Os autores afirmam que professores e alunos são capazes de executar tarefas mais complexas, mas acabam sendo dependentes da tecnologia, ou de alguém para lhes apontar as etapas do procedimento. $\mathrm{O}$ consumo de tecnologia pode, então, trazer eficiência nas tarefas antigas, mas pode gerar dependência na execução, ou seja, a inabilidade na autonomia da ação.

Frota e Borges (2004) apresenta a segunda concepção que está ligada ao incorporar tecnologia, ou seja, apoderar-se das novas tecnologias e das TICs, transformando-as em ferramentas e em instrumentos cognitivos, conseguindo mudar a forma de fazer e de pensar matematicamente por parte do professor e do educando. Os autores afirmam que essa segunda concepção, admite dois níveis de entendimento, onde o primeiro está ligado ao acúmulo de experiências pessoais com o uso da tecnologia, condicionando a quantidade de conhecimento às possibilidades de mudanças nas formas de fazer matemática.

Já no segundo nível dessa concepção, o professor percebe que a incorporação de novas formas de fazer matemática, desenvolve no aluno novas formas de pensar e resolver problemas. Essa incorporação tecnológica possibilita um caráter mais inovador no processo de ensino 


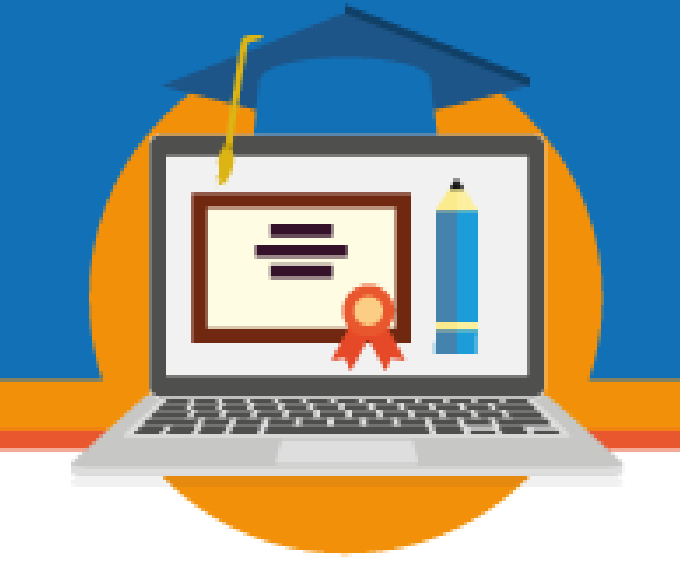

aprendizagem, mas pode acarretar também uma dependência do recurso tecnológico, em que o aluno só conseguirá produzir com o uso das tecnologias.

Frota e Borges (2004) apresentam a terceira e última concepção, em que a tecnologia poderá ser incorporada à Educação Matemática como um objeto curricular de matemática valioso em si e por si mesmo. Denominada pelos autores como "matematizar a tecnologia", eles a divide em dois níveis.

O primeiro nível baseia-se no entendimento de "matematizar a tecnologia enquanto fonte de temas matemáticos é o desvelar a matemática que está em ação nos objetos e processos tecnológicos que usamos no nosso cotidiano" (p.9).

O professor acredita que trabalhando com a matemática em ação, com usos diários, os alunos poderão compreender que a tecnologia também obedece às regras e aos limites estabelecidos à matemática.

O segundo nível exige mais do professor e do aluno, pois é mais avançado e foi denominado pelos autores de "matematizar a tecnologia modelando objetos e processos". Em relação a essa concepção, os autores afirmam que pouquíssimos professores trabalham com essa concepção, seja por problemas na sua formação inicial, ou por obstáculos encontrados no uso das tecnologias. Para os autores a problemática principia nos cursos de licenciatura, uma vez que a formação inicial é diferente da exigência na prática.

Buscando compreender tais concepções, foi criado um blog (2013) visando dar mais ênfase à tecnologia no curso de Pedagogia da UniEVANGÉLICA- Anápolis, o mesmo pode ser encontrado em:

https://simonepaularodrigues2013.wordpress.com/author/simonepaularodrigues/ 


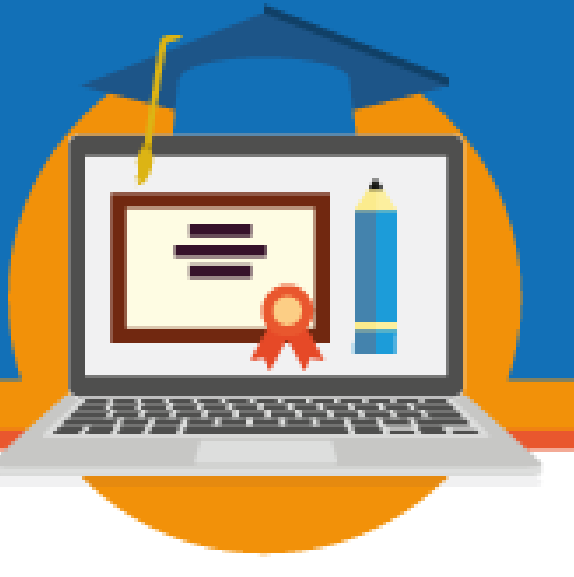

Prof ${ }^{a}$ Ms. Simone Rodrigues

Blog para jogos matemáticos variados. Também voltado para seus alunos no Centro

Universitário de Anápolis

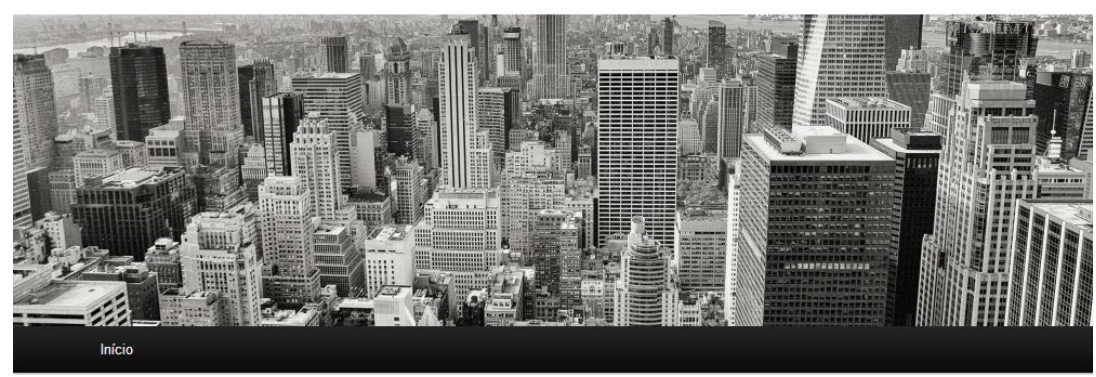

O blog tem 48 posts, com 57238 visualizações e 3079 comentários. Como comprova o print da tela.

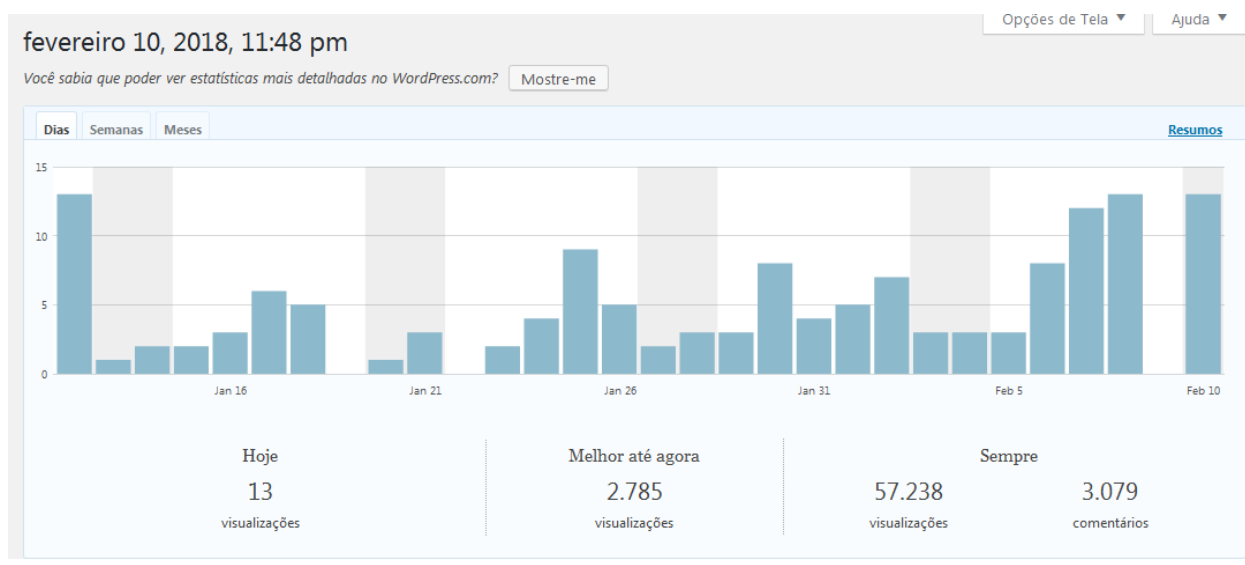

Propôs-se que: todos os acadêmicos deveriam acessar o blog, escolher cinco jogos, jogar e fazer comentários sobre o mesmo.

Nenhum software foi construído pela criadora do blog, todos os links foram copiados de sites de busca, ${ }^{5}$ endereços de grupos de estudo, universidades e pessoas que trabalham com Educação Matemática. Todos os endereços foram acessados entre fevereiro 2013 e 2015, sendo que os créditos foram direcionados aos devidos autores.

\footnotetext{
${ }^{5}$ Sugerimos os sites de busca Google (www.Google.com.br) e Yahoo! (www.yahoo.com.br). 


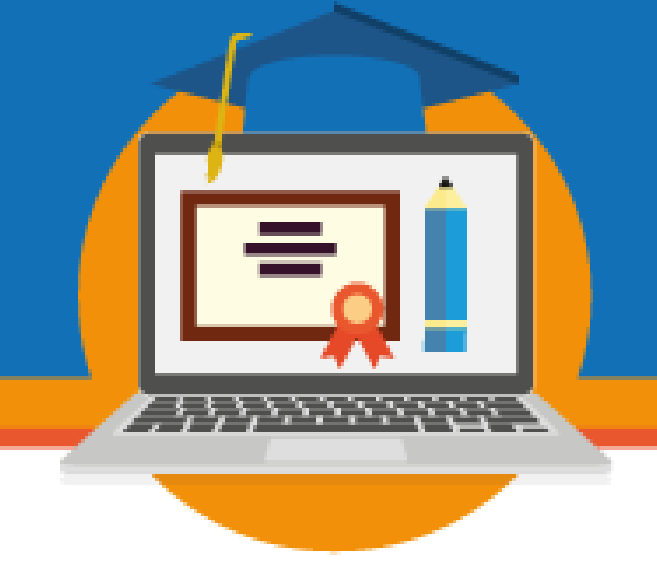

Os cinco softwares mais comentados foram: o jogo do tangram com 190 comentários, torre de hanói com 185, Supermercado virtual com 177 comentários, calculadora quebrada com 141 e fecha a caixa com 121 comentários. Esses dados foram coletados no dia 10 de fevereiro de 2018, como mostra a figura acima.

A preocupação maior da professora foi quanto aos comentários dos acadêmicos sobre o pensar matemático em relação ao uso dos softwares educativos. Pois em praticamente todos os comentários havia somente elogios para os softwares, mesmo quando o acadêmico declarava sua dificuldade em realizar a atividade proposta. Deixando evidentes suas limitações e dificuldades.

Entendemos que os softwares são interfaces constituídas para gerar potencialidades possibilitar comunicação e interação assumindo a relação do homem com as tecnologias como uma analogia intencional.

Por isso criamos o blog, mesmo tendo conhecimento que o seu uso, não é uma das tecnologias mais modernas, visto que a cada dia, a partir da engenhosidade humana, novos artefatos surgem.

Mesmo não sendo uma ferramenta interativa recente, foi observado dificuldades por parte de alguns alunos. Uma delas foi à resistência à inserção ao blog, pois muitos nunca haviam acessado esse espaço, mas com ajuda de colegas e professores esse objetivo foi alcançado.

Outra dificuldade clara foi em relação à falta de conhecimento da matemática para resolver as situações propostas. E a solução encontrada pela professora e acadêmicos foi o print do jogo que possibilitava a comunicação e interação juntamente com outras metodologias.

\section{Considerações Finais}

Como menciona KLUTH, MOURA (2014) educadores matemáticos não podem deixar iludir que o uso da tecnologia para o ensino da matemática instituída possa ser mais abrangente do que sua própria natureza lhe permite. 


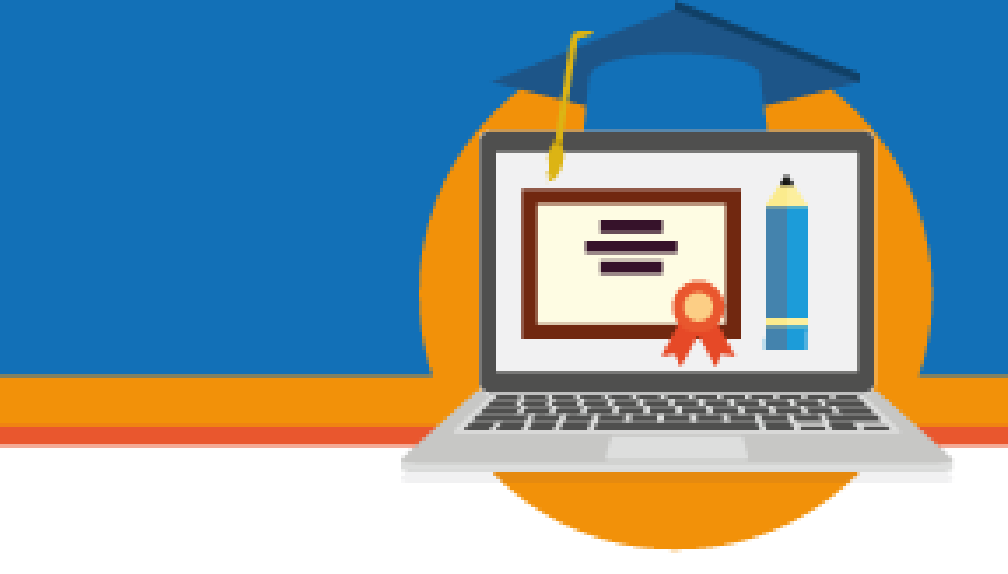

Escola e TICs precisam inserir-se num projeto de reflexão e ação, de forma significativa, com uma visão aberta do mundo contemporâneo, possibilitando um trabalho com diversas experiências e situações pedagógicas diversificadas, permitindo a reelaboração e a reconstrução do processo ensino-aprendizagem.

\section{REFERÊNCIAS BIBLIOGRÁFICAS}

BRASIL - Ministério da Educação - Secretaria de Educação Fundamental - PCN's Parâmetros Curriculares Nacionais. Brasília MEC/SEF, 1998.

CURY, H. N. (org). Disciplinas matemáticas em cursos superiores: reflexões, relatos, propostas. Porto Alegre: EDIPUCRS, 2004.

D’AMBROSIO, U. Educação matemática: da teoria à prática. Campinas, SP: Papirus, 1996.

FIORENTINI, D.; LORENZATO, S. Investigação em educação matemática: percursos teóricos e metodológicos. $2^{\mathrm{a}}$ Ed. rev- Campinas, São Paulo: autores associados, 2007.

FIORENTINI, D. A didática e a prática de ensino mediadas pela investigação sobre a prática. In: ROMANOWSKI, J. P. et al. (Org.) Conhecimento local e conhecimento universal: pesquisa, didática e ação docente. Curitiba: Champanhat, 2004. p.243-257.

FLORIANI, J. V. Professor e pesquisador: exemplificação apoiada na matemática. 2 ed. Blumenau: EdiFurb, 2000. 


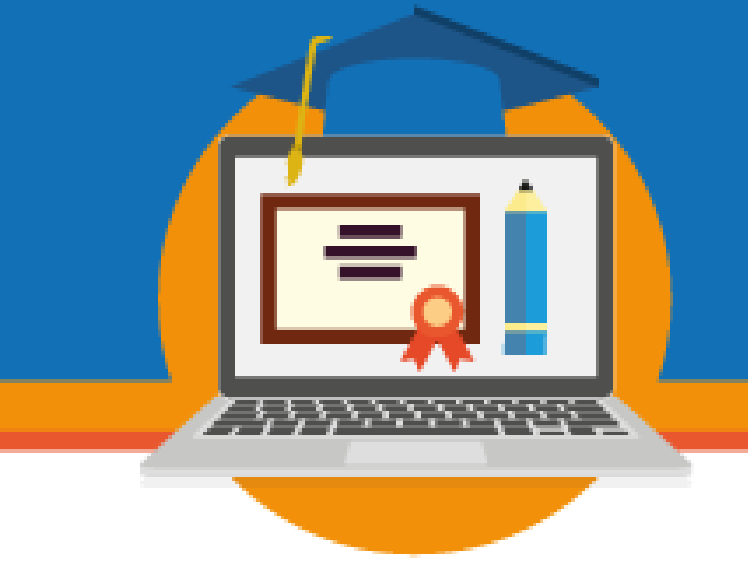

FONSECA, Maria Aparecida Rodrigues da. A Escola de Tempo Integral e a Aprendizagem Mediada pelas Novas Tecnologias Educacionais. Trabalho de conclusão do Curso de Especialização em Metodologia do Ensino Fundamental, do Centro de Ensino e Pesquisa Aplicada à Educação, da Universidade Federal de Goiás. Anápolis 2010.

FROTA, M. C.; BORGES, O. Perfis de entendimento sobre o uso de tecnologias na educação matemática. In: 27a. Reunião Anual da ANPEd, 2004, Caxambu, MG. Sociedade, Democracia e Educação: Qual Universidade? Rio de Janeiro: ANPEd, 2004.

KAWASAKI, T. F. Tecnologias na sala de aula de matemática: resistências e mudanças na formação continuada de professores. 2008. 212f. Tese (Doutorado em Conhecimento e Inclusão Social). Universidade Federal de Minas Gerais, Belo Horizonte, 2008. Disponível em: $<$ http://www.bibliotecadigital.ufmg.br/dspace $\quad /$ bitstream/handle/1843/FAEC$\underline{84 X H 59 / \text { teresinhakawasakitese.pdf?sequence=1 }>\text { Acesso em }: \text { 20/02/2012. }}$.

KLUTH, V. S.; MOURA, S. P. R. Preâmbulos investigativos sobre o uso de softwares como ato propulsor do pensar matemático. In: Maria Aparecida Viggiani Bicudo. (Org.). Ciberespaço - Possiblidades para o mundo da educação. 1ed.São Paulo: Livraria da Física, 2014, v. 1, p. 221-247

NACARATO, A. M.; MEGALI, B. L. S.; PASSOS, C. L. B. A matemática nos anos iniciais do ensino fundamental: Tecendo fios do ensinar e do aprender. Belo Horizonte: Autêntica Editora, 2009.

NETO, S. P. Entrevista. Educação Matemática em Revista. n. 9/10, 2001, p.5-9.

PORTANOVA, R. (org) Um currículo de matemática em movimento. Porto Alegre: EDIPUCRS, 2005.

SKOVSMOSE, O. e VALERO, P. Breaking political neutrality: the critical engagement of mathematics education with democracy. In: ATEWEH, Bill et alii. Sociocultural research on mathematics education: an international perspective. Lawrence Erlbaun Associates: London, 2001.

SOUZA, A. C. C. de. Sensos matemáticos: uma abordagem externalista da matemática. F. E. UNICAMP/DEME. Campinas: 1992. 


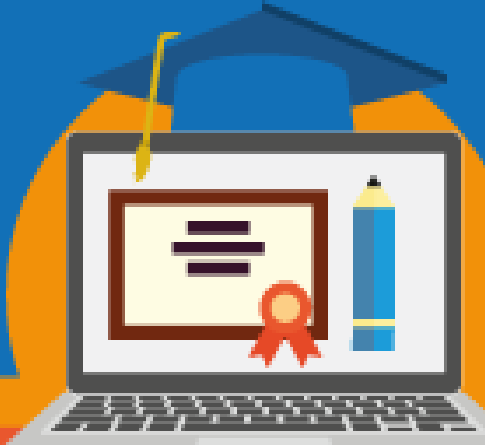

II SEMINÁRIO DE EDUCAÇÃO A DISTÂNCIA

EaD na região Centro-Oeste: Institucionalização, Limites e Potencialidades

12 a 14 de abril de 2018 - Campo Grande/MS 